\title{
Pendapatan dan Efisiensi Teknis Usaha Tani Jernang (Daemonorops Draco) di Desa Lamban Sigatal Kecamatan Pauh Kabupaten Sarolangun Provinsi Jambi
}

\author{
${ }^{1}$ Siti Abir Wulandari dan ${ }^{2}$ Jonathan Tio Pande Simbolon \\ ${ }^{1}$ Program Studi Agribisnis Universitas Batanghari ${ }^{1}$ \\ ${ }^{2}$ Alumni Program Studi Agribisnis Universitas Batanghari ${ }^{2}$ \\ Jalan Slamet Riyadi-Broni Jambi, 36122. Tel. +624160103 \\ 1e-mail korespondensi : $\underline{\text { siti.abir.wulandari@unbari.ac.id }}$
}

\begin{abstract}
The purpose of this research was to find out; to describe the jernang farming activities, analyzing production costs and jernang farming income and analyze tecnic efficience jernang farming. This research was conducted in Lamban Sigatal Village, Pauh District, Sarolangun Regency, Jambi Province. The analytical method used in this study was descriptive. Results of study indicated that jernang plants use organic and inorganic fertilizers. Fertilizer was given in several stages, first given before or at the same time as planting, fertilizer was inserted into the planting hole at a dose of $2 \mathrm{~kg}$ per planting hole or NPK $100 \mathrm{~g}$ per planting hole. Furthermore, continued fertilizer was started after the plants were 6 months, NPK with doses between 50-100 grams per plant which was done every 6 months. Fertilization of compost or manure was also done by placing it around the plants. Harvesting of fruit was done once every 3 months to get optimal results and the average yield of jernang was 1,080 $\mathrm{Kg} /$ Period. Marketing was done indirectly by delivering it to the buyer's location. The average production of jernang was 1.080 Kg/Period and the average total cost was Rp. 10,597,544 /Period consists Rp. 70,550/Period as fixed cost and a variable cost of Rp. 10,526,993 /Period. The average farmers revenue was Rp. 86.400.000 / Period, the income was Rp. 75,802,456/Period. The average technical efficiency achieved by farmers was $98 \%$. In a view of the distribution, the technical efficiency achieved by respondent farmers was spread in the range of $97.7 \%$ to 99.8\%. Jernang farmers were already efficience because the level of technical efficiency was considered high it was showing that farmers had implemented the jernang farming business system well.
\end{abstract}

Keywords : Farmer, Income, Technical Efficience, Jernang

\begin{abstract}
Abstrak. Tujuan penelitian ini adalah untuk mengetahui gambaran kegiatan usaha tani jernang, menganalisis biaya produksi dan pendapatan serta menganalisis efisiensi teknis pada usahatani jernang. Hasil penelitian menunjukkan tanaman jernang menggunakan pupuk organik dan anorganik. Pupuk diberikan dengan beberapa tahapan, pertama diberikan sebelum atau bersamaan dengan waktu penanaman, pupuk dimasukkan ke dalam lubang tanam dengan dosis $2 \mathrm{~kg}$ per lubang tanam atau NPK 100 gr per lubang tanam. Selanjutnya pupuk lanjutan dimulai setelah tanaman berumur 6 bulan. NPK dengan dosis antara 50100 gram per tanaman yang dilakukan setiap 6 bulan. Pemupukan pupuk kompos atau pupuk kandang juga dilakukan dengan cara diletakkan disekitar tanaman. Pemanenan buah rata-rata dilakukan 3 bulan sekali untuk mendapatkan hasil yang optimal dan rata-rata hasil produksi jernang adalah $1.080 \mathrm{Kg} /$ Periode. Pemasaran dilakukan secara tidak langsung dengan mengantarkan hasil jernang ke lokasi pembeli. Rata-rata hasil produksi jernang adalah $1.080 \mathrm{Kg} /$ Periode, dan rata-rata total biaya adalah sebesar Rp. 10.597.544 /Periode terdiri dari biaya tetap sebesar Rp. 70.550/Periode dan biaya tidak tetap sebesar Rp. 10.526.993//Periode. Rata-rata penerimaan yang diperoleh petani sebesar Rp. 86.400.000/Periode, pendapatan sebesar Rp. 75.802.456/Periode. Rata-rata efisiensi teknis yang dicapai petani jernang adalah sebesar 98\%. Apabila dilihat dari sebarannya, efisiensi teknis yang dicapai oleh petani responden ada pada kisaran 97,7 \% sampai 99,8\%. Petani jernang sudah efisien, karena tingkat efisiensi teknis dinilai sudah tinggi menunjukkan petani sudah menerapkan sistem usaha tani jernang dengan baik

Kata kunci : Petani, Pendapatan, efisiensi teknis, Jernang
\end{abstract}

\section{PENDAHULUAN}

Rotan jernang merupakan hasil hutan bukan kayu (HHBK) yang memiliki nilai ekonomi yang tinggi. Getah rotan jernang (jernang) merupakan getah termahal sampai dengan saat ini. Rotan jernang merupakan penghasil resin yang bernilai tinggi berupa jernang (dragon blood). Jernang ini masih diambil dari hutan alam, sehingga produktivitasnya sangat tergantug pada kondisi hutan. Keberadaan rotan jernang terus menurun akibat praktik pemanenan yang tidak lestari, illegal loging, kebakaran hutan dan perubahan fungsi lahan. Permintaan jernang untuk ekspor masih tinggi sehingga perlu dilakukan budidaya secara luas untuk menjamin produktivitas (Sahwalita, 2014)

Jernang bermanfaat sebagai bahan pewarna vernis, keramik, marmer, alat dari batu, kayu, rotan, bambu, kertas, cat dan sebagainya. Selain itu juga digunakan sebagai bahan obat-obatan seperti obat diare, disentri, obat luka, serbuk untuk gigi, asma, sipilis, berkhasiat aphrodisiac (meningkatkan libido) serta banyak kegunaan lainnya (Waluyo, 2017). Selanjutnya rotan jernang bisa dijadikan anyaman Tudung Saji, Ronjong, Ragak, Ayak Padi, Kampit (Sarikun et al., 2019)

Di Desa Lamban Sigatal Kecamatan Pauh Kabupaten Sarolangun Provinsi Jambi petani jernang sudah lama memanen rotan jernang dari alam dan menjualnya kepada pengumpul yang ada di desa. Secara umum masyarakat belum mengetahui manfaat dari produk akhir resin jernang. Masyarakat hanya melakukan perburuan terhadap 
jernang dengan memanen dari hutan, yang mereka tahu adalah jernang itu merupakan penghasilan yang menjanjikan dengan harga yang tinggi (Wicaksono \& Adhi, 2014).

Pada tahun 2015, himbauan untuk membudidayakan tanaman jernang terus dilakukan, agar petani tidak hanya bisa memungut jernang hasil hutan tetapi juga bisa memungut jernang hasil budidaya. Sejak saat itu budidaya tanaman jernang mulai diusahakan oleh petani di Desa Lamban Sigatal Kabupaten Sarolangun. Pada tahun 2021 usahatani jernang yang dilakukan petani mulai berproduksi tetapi petani belum melakukan perhitungan berapa besar biaya dan pendapatan yang diterimanya. Penghitungan pendapatan merupakan suatu unsur yang harus dilakukan dalam melakukan suatu usahatani, petani yang melakukan usahatani jernang tidak menghitung berapa biaya dan keuntungan yang diterima dari usahataninya Pendapatan usaha tani yang diterima berbeda untuk setiap orang, perbedaan pendapatan ini dipengaruhi oleh berbagai faktor. Faktor-faktor ini ada yang masih dapat diubah dalam batas-batas kemampuan petani atau tidak dapat diubah sama sekali. Faktor yang tidak dapat diubah adalah iklim, jenis tanah dan umur tanaman, semakin tua umur tanaman maka semakin sedikit buah yang dihasilkan. Ada juga faktor yang mempengaruhi pendapatan dan dapat dilakukan perbaikan untuk meningkatkan pendapatan seperti pemeliharaan tanaman selama masa produktif. Untuk menghasilkan hasil panen yang lebih tinggi diperlukan pemeliharaan tanaman jernang yang optimal. Hubungan antara produksi jernang dengan berbagai input usahatani yang digunakan dalam pemeliharaan tanaman (penggunaan bibit unggul, penggunaan pupuk, aplikasi obat-obatan tanaman, aplikasi pengendalian gulma, penggunaan tenaga kerja, dan lainnya) secara fungsional merupakan fungsi produksi tanaman jernang. Pada teknologi usahatani tertentu, produksi yang tinggi bisa dicapai apabila menggunakan kombinasi input dengan jumlah cukup, kualitas baik, dan waktu tepat. Produksi yang tinggi mencapai atau mendekati frontiernya menunjukkan bahwa produksi jernang petani telah efisien secara teknis. Sebaliknya pencapaian produksi yang rendah akan menghasilkan pendapatan usahatani cenderung rendah, tetapi juga dalam proses produksinya tidak efisien secara teknis

\section{METODE PENELITIAN}

Metode penelitian yang digunakan dalam penelitian ini adalah metode survey. Penelitian ini dilakukan pada petani jernang di Desa Lamban Sigatal Kecamatan Pauh Kabupaten Sarolangun Provinsi Jambi. Dipilihnya daerah ini sebagai lokasi penelitian dengan pertimbangan bahwa Desa Lamban Sigatal Kecamatan Pauh Kabupaten Sarolangun merupakan salah satu sentra produksi jernang.

Metode analisis hasil dilakukan dengan cara deskriptif kualitatif, yaitu diperoleh dari hasil laporan wawancara dan hasil pengamatan. Selanjutnya untuk mengetahui keseluruhan biaya pada usahatani jernang di Desa Lamban Sigatal Kecamatan Pauh Kabupaten Sarolangun Provinsi Jambi dengan menggunakan rumus besarnya biaya pada usaha tani menurut Soekartawi (2002) sebagai berikut:

$\mathrm{TC}=\mathrm{TFC}+\mathrm{TVC}$

Keterangan :

$\mathrm{TC}=$ Total Biaya $(\mathrm{Rp} /$ Periode $)$

$\mathrm{TFC}=$ Total Biaya Tetap (Total Fixed Cost $)(\mathrm{Rp} /$ Periode $)$

$\mathrm{TVC}=$ Total Biaya Variabel $($ Total Variavel Cost $)(\mathrm{Rp} /$ Periode $)$

Untuk menghitung besarnya penerimaan ditentukan dengan menggunakan rumus menurut (Suratiyah, 2015) sebagai berikut:

Penerimaan $=\mathrm{Py} . \mathrm{Y}$

Keterangan :

$\mathrm{P} \quad=$ Penerimaan $(\mathrm{Rp} /$ Periode $)$

Py $\quad=$ Harga Produk $(\mathrm{Rp} / \mathrm{Kg})$

$\mathrm{Y} \quad=$ Jumlah produksi kering atau basah $(\mathrm{Rp} /$ Periode $)$

Untuk mengetahui pendapatan diperoleh dengan cara mengurangkan total penerimaan dengan total biaya menurut Soekartawi (2002) dengan rumus sebagai berikut:

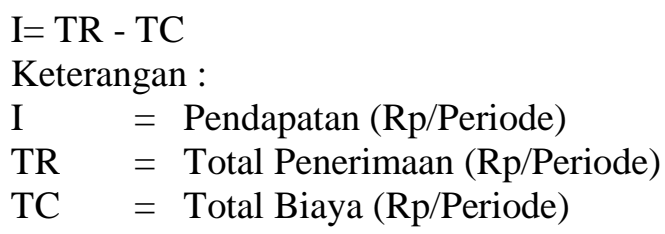


Untuk mengetahui biaya penyusutan menurut (Suratiyah, 2015) biaya dengan penyusutan dihitung dengan rumus sebagai berikut:

\begin{tabular}{|c|c|}
\hline \multicolumn{2}{|c|}{ Penyusutan $=$ Nilai Awal - Nilai Akhir } \\
\hline Keterangan : & \\
\hline Penyusutan & $=$ Biaya Penyusutan $(\mathrm{Rp} /$ Periode $)$ \\
\hline Nilai Awal & $=$ Total Penerimaan $(\mathrm{Rp} /$ Periode $)$ \\
\hline Nilai Akhir & $=$ Total Biaya $(\mathrm{Rp} /$ Periode $)$ \\
\hline Umur Ekonomis & $=$ Berapa lama $($ periode $)$ \\
\hline
\end{tabular}

Data yang diperoleh dilakukan pengolahan untuk mengestimasi fungsi produksi dan tingkat efisiensi teknis usahatani jernang di desa Lamban Sigatal. Pengolahan data dilakukan melalui dua tahap. Tahap pertama merupakan pendugaan parameter $\beta_{\mathrm{i}}$ pada fungsi produksi frontier stokastik menggunakan ordinary least squares methods (OLS). Tahap ini dilakukan menggunakan software frontier 4.1c untuk memeriksa terpenuhinya asumsi regresi linier klasik (normalitas, homoskedastisitas, dan multikolinieritas). Apabila model dianggap telah fitted dan memenuhi kriteria BLUE (best linear unbiased estimator), maka analisis dapat dilanjutkan ke tahap kedua. Tahap kedua merupakan pendugaan seluruh parameter $\beta_{0}, \beta_{\mathrm{i}}$, dan varians dari $\mathrm{v}_{\mathrm{i}}$ dan $\mathrm{u}_{\mathrm{i}}$ menggunakan maximum likelihood estimation methods (MLE).

Model fungsi produksi yang digunakan dalam penelitian ini adalah fungsi produksi Cobb-Douglas. (Debertin, 2013) menyebutkan bahwa fungsi produksi Cobb-Douglas merupakan mode 1 fungsi yang paling sering digunakan dalam analisis proses produksi pertanian. Selain itu, pemilihan penggunaan fungsi produksi Cobb-Douglas dalam penelitian ini adalah karena fungsi produksi Cobb-Douglas memiliki beberapa keunggulan, di antaranya: 1). Estimasi fungsi produksi Cobb-Douglas lebih mudah karena bisa dengan mudah ditransformasi ke bentuk linier melalui logaritma; 2). Koefisien fungsi produksi Cobb-Douglas langsung menunjukkan elastisitas produksi parsial dari variabel penjelas dalam model; dan 3). Jumlah seluruh besaran elastisitas (nilai koefisien variabel penjelas) menunjukkan skala usaha (returns-to-scale), dan jika lebih besar dari 1 (satu) menunjukkan skala usaha yang meningkat (increasing returns-to-scale); sama dengan satu menunjukkan skala usaha tetap (constant returns-toscale); dan kurang dari satu menunjukkan skala usaha menurun (decreasing returns-to-scale).

Model frontier stokastik Cobb-Douglas digunakan dalam pendugaan fungsi produksi usahatani jernang di desa Lamban Sigatal. Bentuk fungsi produksi frontier stokastik Cobb-Douglas yang telah ditransformasi ke bentuk linier adalah (Aigner et al., 1977):

$\ln Y=\beta_{0}+\beta_{1} \ln S_{1}+\beta_{2} \ln S_{2}+\beta_{3} \ln S_{3}+\beta_{4} \ln S_{4}+\left(v_{i}-u_{i}\right)$

dimana:

$\mathrm{Y}=$ produksi getah jernang $(\mathrm{Kg} /$ periode $)$

$\beta_{0}=$ konstanta, dan $\beta_{\mathrm{i}}=$ koefisien $(\mathrm{i}=1,2,3, \ldots 7)$

$\mathrm{v}_{\mathrm{i}} \quad=$ komponen error stokastik; $\mathrm{u}_{\mathrm{i}}=$ komponen error dari efek inefisiensi.

$\mathrm{S}_{1} \quad=$ luas lahan jernang produktif $(\mathrm{Ha})$

$\mathrm{S}_{2}=$ jumlah bibit $(\mathrm{Kg} /$ periode $)$

$\mathrm{S}_{3}=$ jumlah pupuk $(\mathrm{Kg} /$ periode $)$

$\mathrm{S}_{4}=$ penggunaan Obat-obatan (ltr/periode)

Nilai koefisien yang diharapkan setelah dilakukan pendugaan fungsi produksi usahatani jernang petani di desa Lamban Sigatal, yaitu $\beta_{1}, \beta_{2}, \beta_{3}, \beta_{4}, \beta_{5}, \beta_{6}, \beta_{7}>0$. Koefisien $\beta_{i}$ yang lebih besar dari nol, diharapkan memberikan pengaruh positif masing masing variabel penjelas terhadap produksi jernang petani.

Pengukuran efisiensi teknis bisa dilakukan dari hasil estimasi fungsi produksi frontier stokastik Cobb-Douglas menggunakan rasio antara produksi jernang pengamatan (actual) dengan kemungkinan maksimum produksi jernang berdasarkan frontier stokastik ( predict) produksi jernang petani sampel di desa Lamban Sigatal, sebagaimana sebagai berikut:

$T E_{j}=\frac{T B S_{j}}{e^{\left(X_{j} \beta_{j}+v_{j}\right)}}=\frac{e^{\left(X_{j} \beta_{j}+v_{j}-u_{j}\right)}}{e^{\left(X_{j} \beta_{j}+v_{j}\right)}}=\frac{\exp \left(X_{j} \beta_{j}+v_{j}-u_{j}\right)}{\exp \left(X_{j} \beta_{j}+v_{j}\right)}=\exp \left(-u_{j}\right)$

dimana:

$T E_{j} \quad=$ efisiensi teknis usahatani jernang petani ke-j.

$T B S_{j} \quad=$ produksi aktual usahatani jernang petani ke-j.

$\exp \left(X_{j} \beta_{j}+v_{j}\right)=$ prediksi produksi frontier stokastik jernang petani ke-j. 
Indeks efisiensi teknis berada pada kisaran nol hingga satu $(0<\mathrm{TE}<1)$. Indeks efisiensi teknis bernilai satu artinya unit produksi telah efisien secara teknis sepenuhnya atau secara teknis pencapaian produksi maksimum sesuai teknologi yang diadopsi petani. Sebaliknya, bila indeks efisiensi teknis semakin mendekati nol maka pencapaian efisiensi teknis rendah atau inefisiensi teknis.

\section{A. Identitas Petani Umur Petani}

Secara umum umur atau usia merupakan satuan waktu yang mengukur waktu keberadaan suatu benda atau makhluk baik yang hidup maupun yang mati. Menurut Nursalam (2011), semakin cukup umur maka tingkat kematangan dan kekuatan seseorang akan lebih matang dalam berpikir dan bekerja. Dari segi kepercayaan masyarakat yang lebih dewasa akan lebih percaya dari pada orang yang belum cukup tinggi kedewasaannya. Hal ini sebagai akibat dari pengalaman jiwa. Umur dapat mempengaruhi kemampuan seseorang untuk bekerja dan mengelola usaha taninya baik itu pada proses produksi atau pada pengolahan lahan pertanian. Semakin tinggi umur petani maka kemampuan fisik petani untuk bekerja pada lahan usaha taninya relatif menurun karena pada umumnya pekerjaan usaha tani petani mengandalkan kekuatan fisik atau tenaga dalam kegiatan produksi. Untuk lebih jelasnya jumlah petani berdasarkan umur di Desa Lamban Sigatal Kecamatan Pauh dapat dilihat pada Tabel 1.

Tabel 1. Distribusi Frekuensi Petani Berdasarkan Umur di Desa Lamban Sigatal Tahun 2021

\begin{tabular}{cccc}
\hline No & Umur (Tahun) & Frekuensi (RTP) & Persentase (\%) \\
\hline 1 & $29-34$ & 3 & 20 \\
2 & $35-40$ & 4 & 26,66 \\
3 & $41-46$ & 6 & 40 \\
4 & $47-52$ & 1 & 6,67 \\
5 & $53-58$ & 1 & 6,67 \\
\hline
\end{tabular}

Sumber : Data Primer yang diolah 2021

Tabel 1 menunjukkan bahwa petani jernang paling banyak berada pada interval umur 41-46 tahun dengan jumlah 6 RTP (40\%), sedangkan petani jernang paling sedikit berada pada interval umur 47-52 tahun dan 53-58 tahun dengan jumlah masing-masing 1 RTP (6,67\%). Rata-rata umur petani jernang di Desa Lamban Sigatal Kecamatan Pauh Kabupaten Sarolangun adalah 40 tahun. Angka ini termasuk kedalam golongan usia produktif (antara 15 sampai 64 tahun) sedangkan golongan usia tidak produktif (di bawah 15 tahun dan 65 tahun ke atas) (Statistik, 2018). Petani jernang di Desa Lamban Sigatal Kecamatan Pauh Kabupaten Sarolangun masih berada dalam usia produktif, sehingga petani mempunyai kemampuan yang kuat untuk berusaha.

\section{Pendidikan Petani}

Pendidikan adalah hal yang sangat penting dalam kehidupan sebagai dasar memperoleh pengetahuan dan keterampilan. Tingkat pendidikan merupakan salah satu faktor yang mempengaruhi kemampuan dan pemahaman seseorang terhadap sesuatu yang diterimanya. Pendapatan yang diperoleh akan semakin meningkat sesuai dengan tingkat pendidikan yang dicapai. Akhirnya, pendidikan dapat meningkatkan kemungkinan perubahan sikap individu sehubungan dengan keinginan partisipasi kerja (Satrio \& Aji, 2016). Tingkat pendidikan petani berdasarkan tingkat pendidikan formal yang ditempuh dapat dilihat pada Tabel 2 sebagai berikut :

Tabel 2. Distribusi Frekuensi Petani Berdasarkan Tingkat Pendidikan Di Desa Lamban Sigatal 2021

\begin{tabular}{clcc}
\hline No & \multicolumn{1}{c}{ Pendidikan } & Frekuensi (RTP) & Persentase (\%) \\
\hline 1 & Tidak Sekolah & 1 & 6,67 \\
2 & Tidak Tamat SD & 2 & 13,33 \\
3 & SD & 8 & 53,33 \\
4 & SLTP & 3 & 20 \\
5 & SLTA & 1 & 6,67 \\
\hline & & 15 & 100 \\
\hline
\end{tabular}

Sumber : Data Primer yang diolah 2021

Berdasarkan Tabel 2 terlihat bahwa tingkat pendidikan petani di Desa Lamban Sigatal Kecamatan Pauh mulai dari tidak bersekolah sampai dengan SLTA, mayoritas tingkat pendidikan petani adalah SD yaitu sebanyak 8 RTP $(53,33 \%)$ dan hanya terdapat 1 orang atau $6,67 \%$ yang tidak sekolah. Hal ini menunjukkan bahwa pendidikan petani di Desa Lamban Sigatal Kecamatan Pauh tergolong rendah. Rendahnya tingkat pendidikan petani akan 
berpengaruh pada pola pikir dalam melakukan dan untuk perencanaan yang baik akan berpengaruh langsung terhadap produksi yang dihasilkan petani dalam usaha taninya.

\section{Jumlah Tanggungan Keluarga Petani}

Jumlah tanggungan keluarga merupakan salah satu faktor yang mempengaruhi keberhasilan, semakin banyak jumlah tanggungan keluarga maka semakain banyak kebutuhan yang akan dipenuhi oleh petani tetapi disisi lain semakin banyak tanggungan keluarga petani maka semakin banyak tersedia tenaga kerja yang dimanfaatkan untuk membantu menggelolah usaha yang dijalankan, untuk lebih jelas jumlah tanggungan petani dapat dilihat pada Tabel 3.

Tabel 3. Distribusi Frekuensi Petani Berdasarkan Jumlah Tanggungan Di Desa Lamban Sigatal Tahun 2021

\begin{tabular}{cccc}
\hline No & Jumlah Tanggungan Keluarga (Orang) & Frekuensi (RTP) & Persentase (\%) \\
\hline 1 & 2 & 2 & 13,33 \\
2 & 3 & 2 & 13,33 \\
3 & 4 & 8 & 53,33 \\
4 & 5 & 1 & 6,67 \\
5 & 6 & 2 & 13,33 \\
\hline & Jumlah & 15 & 100
\end{tabular}

Sumber : Data Primer yang diolah 2021

Berdasarkan Tabel 3 terlihat bahwa rata-rata jumlah tanggungan keluarga petani di Desa Lamban Sigaal Kecamatan Pauh adalah 4 orang. Tabel 3 menunjukkan bahwa mayoritas petani memiliki jumlah tanggungan keluarga sebanyak 4 orang dengan jumlah petani 8 RTP $(53,33 \%)$ dan paling sedikit memiliki tanggungan 5 orang dengan jumlah sebanyak 1 RTP $(6,67 \%)$.

\section{Luas Lahan Usahatani}

Luas lahan adalah berapa banyak lahan yang digarap oleh petani dalam kegiatan usahataninya. Semakin banyak jumlah luas lahan yang dimiliki oleh petani maka semakin besar peluang untuk memperoleh produksi yang relatif besar. Luas lahan di Desa Lamban Sigatal Kecamatan Pauh memiliki luas lahan yang bervariasi dapat dilihat pada Tabel 4.

Tabel 4. Distribusi Frekuensi Petani Berdasarkan Luas Lahan Di Desa Lamban Sigatal Tahun 2021

\begin{tabular}{cccc}
\hline No & Luas Lahan $(\mathbf{H a})$ & Frekuensi (RTP) & Persentase (\%) \\
\hline 1 & $0,25-0,50$ & 4 & 26,66 \\
2 & $0,51-0,76$ & 0 & 0 \\
3 & $0,77-1,02$ & 8 & 53,33 \\
4 & $1,03-1,28$ & 2 & 13,33 \\
5 & $1,29-1,54$ & 1 & 6,67 \\
\hline & Jumlah & 15 & 100 \\
\hline
\end{tabular}

Sumber : Data Primer yang diolah 2021

Hasil penelitian menunjukkan bahwa rata-rata luas lahan yang dimiliki oleh petani di Desa Lamban Sigatal Kecamatan Pauh adalah $1 \mathrm{Ha}$. Tabel 4 menunjukkan bahwa paling banyak petani memiliki luas lahan pada interval 0,77-1,02 Ha dengan jumlah 8 RTP $(53,33 \%)$ dan paling sedikit petani yang memiliki luas lahan pada interval 1,291,54 Ha dengan jumlah 1 RTP.

\section{B. Gambaran Kegiatan Usahatani Jernang Di Desa Lamban Sigatal}

Usahatani jernang merupakan tanaman yang telah dibudidayakan di Desa Lamban Sigatal Kecamatan Pauh dan merupakan salah satu usahatani yang memiliki potensi cukup besar, karena harga jual jernang yang yang tinggi. Pada saat ini usahatani jernang menjadi salah satu sumber mata pencaharian bagi masyarakat di Desa Lamban Sigaal Kecamatan Pauh.

Petani jernang membuat kelompok tanaman karena tanaman jernang memerlukan perawatan intensif dimana setiap hari petani harus menjaga dan mengontrol tanaman jernang. Bibit yang digunakan oleh petani dbeli dari tokotoko pertanian dengan harga Rp. 10.000 untuk setiap kecambah jernang super per bibit dan Rp. 17.500 untuk setiap bibit tanaman jernang setinggi $30 \mathrm{~cm}$ per jernangnya.

Selanjutnya untuk pupuk diperoleh dari subsidi kelompok tani dan obat-obatan yang digunakan adalah jenis Fortune dibeli dari toko pertanian yang ada di pasar. Tenaga kerja pada usaha tani jernang di Desa Lamban Sigaal 
Kecamatan Pauh rata-rata menggunakan tenaga kerja dari kerabat keluarga dan tetangga untuk meminimalisirkan biaya yang dikeluarkan.

Pada kegiatan budidaya tanaman jernang pembersihan lahan dilakukan dengan cara manual dengan menggunakan alat sabit dan cangkul. Jarak tanam jernang disesuaikan dengan kondisi lahan, yaitu $6 \mathrm{~m}$ x $3 \mathrm{~m}$ atau $8 \mathrm{~m}$ x $4 \mathrm{~m}$. Pola tanaman monokultur yang berarti hanya terdapat satu jenis tanaman yaitu jernang. Praktik penanaman dilakukan secara serentak.

Pemeliharaan tanaman jernang untuk mempercepat pertumbuhan dan meningkatkan produktivitas buah jernang, di Desa Lamban Sigatal Kecamatan Pauh dilakukan dengan cara penyulaman, penyiangan gulma, pemupukan, pengurangan anakan, dan pengendalian hama/penyakit.

Kegiatan penyulaman merupakan kegiatan penanaman yang dilakukan untuk mempertahankan jumlah tanaman pada satuan luas tertentu. Bibit untuk penyulaman telah diperhitungkan dari persiapan bibit di awal penanaman sebelumnya. Harga bibit Rp. 10.000 per kecambah dan Rp. 20.000 per bibit setinggi $20 \mathrm{~cm}$.

Pemberian obat-obatan herbisida dan pupuk yang digunakan adalah jenis organik dan anorganik. Pemupukan terhadap tanaman jernang dilakukan sepanjang umurnya karena tanaman ini memerlukan banyak nutrisi untuk menghasilkan buah yang berlimpah dan anakan untuk membentuk rumpun. Pupuk diberikan dengan beberapa tahapan, pertama diberikan sebelum atau bersamaan dengan waktu penanaman, pupuk dimasukkan ke dalam lubang tanam dengan dosis $2 \mathrm{~kg}$ per lubang tanam atau NPK 100 gr per lubang tanam. Selanjutnya pupuk lanjutan dimulai setelah tanaman berumur 6 bulan. Secara teknis pemupukan dilakukan pada akhir musim kemarau atau awal musim penghujan. Jenis pupuk yang digunakan adalah pupuk majemuk, yaitu NPK dengan dosis antara 50-100 gram per tanaman yang dilakukan setiap 6 bulan. Pemupukan pupuk kompos atau pupuk kandang juga dilakukan dengan cara diletakkan disekitar tanaman.

Pemasaran tanaman jernang dilakukan secara tidak langsung diambil ke petani, sehingga petani memerlukan mengeluarkan biaya transportasi untuk proses pemasarannya. Proses pemanenan tanaman jernang dilakukan harus dengan cara yang benar agar resin yang diperoleh meningkat dan kelestarian jernang terjaga.

Alat pemanenan tanaman jernang tergantung pada tinggi batang. Untuk tinggi batang yang tidak terlalu tinggi menggunakan pisau atau gunting stek dan untuk batang yang tinggi menggunakan egrek. Semua peralatan yang digunakan harus tajam, dengan tujuan agar pada saat panen buah tidak rontok. Pemanenan dilakukan dengan memotong bagian pangkal tandan dengan alat panen. Setelah panen tandan buah dikumpulkan untuk memudahkan pengangkutan. Namun jika pemanenan dilakukan dengan jarak cukup dekat dengan pengepul biasanya buah dibawah langsung beserta tandannya.

\section{Biaya Produksi Usahatani Jernang}

Biaya produksi adalah total biaya yang digunakan dalam proses produksi yang terdiri dari biaya tetap dan biaya tidak tetap (variabel). Biaya tetap adalah biaya yang dikeluarkan dalam proses produksi yang tidak habis pakai dalam satu kali produksi alat-alatnya terdiri dari sabit, cangkul, egrek, gunting stek, lori, pompa air, dan selang air. Sedangkan biaya tidak tetap (variabel) adalah biaya yang digunakan habis pakai dalam satu kali produksi terdiri dari bibit, pupuk kandang, pupuk NPK, pupuk urea, obat-obatan dan bensin. Untuk lebih jelasnya rata-rata jumlah komponen biaya yang dikeluarkan dalam usahatani jernang di daerah penelitian dapat dilihat pada Tabel 5 sebagai berikut:

Tabel 5. Rata-Rata Jumlah Komponen Biaya Produksi Jernang Di Desa Lamban Sigatal Kecamatan Pauh Sarolangun Tahun 2021

\begin{tabular}{clcc}
\hline No & \multicolumn{1}{c}{ Uraian Komponen Biaya } & Jumlah (Rp/Periode) & Persentase (\%) \\
\hline 1 & Biaya Tetap & & \\
& 1. Cangkul & 6.451 & 0,06 \\
2. Sabit & 2.495 & 0,02 \\
& 3. Egrek & 25.462 & 0,24 \\
& 4. Gunting Stek & 593 & 0,01 \\
& 5. Lori & 13.603 & 0,13 \\
6. Selang Air & 14.970 & 0,07 \\
7. Pompa Air & $\mathbf{7 0 . 5 5 0}$ & 0,14 \\
\hline Jumlah Biaya Tetap & & $\mathbf{0 , 6 7}$ \\
\hline 2 & Biaya Tidak Tetap & 13.500 & 0,13 \\
& 1. Bibit & 2.850 .000 & 26,89 \\
& 2. Pupuk Kandang & 4.440 .000 & 41,90 \\
& 3. Pupuk NPK & 3.170 .000 & 29,91 \\
& 4. Pupuk Urea & 33.493 & 0,32
\end{tabular}


Siti Abir Wulandari dan Jonathan Tio Pande Simbolon. Pendapatan dan Efisiensi Teknis Usaha Tani Jernang (Daemonorops Draco) di Desa Lamban Sigatal Kecamatan Pauh Kabupaten Sarolangun Provinsi Jambi

\begin{tabular}{lcc} 
6. Bensin & 20.000 & 0,19 \\
\hline Jumlah Biaya Tidak Tetap & $\mathbf{1 0 . 5 2 6 . 9 9 3}$ & $\mathbf{9 9 , 3 3}$ \\
\hline Total Biaya & $\mathbf{1 0 . 5 9 7 . 5 4 4}$ & $\mathbf{1 0 0}$ \\
\hline
\end{tabular}

Sumber : Data Primer yang diolah 2021

Berdasarkan tabel tersebut maka dapat diketahui bahwa total biaya produksi petani jernang di Desa Lamban Sigatal sebesar Rp.10.597.544/periode. Terdiri dari biaya tetap sebesar Rp. 70.550 dan biaya tidak tetap sebesar Rp. 10.526.993, untuk biaya tetap terkecil terdapat pada komponen gunting stek sebesar Rp.593 /periode dan biaya tetap terbesar pada komponen egrek sebesar Rp.25.462 /periode. Kemudian untuk biaya tidak tetap terkecil terdapat pada komponen bibit sebesar Rp.13.500 /periode dan biaya tidak tetap terbesar pada komponen pupuk NPK sebesar Rp.4.440.000 /periode.

\section{Penerimaan Usahatani Tanaman Jernang}

Penerimaan adalah nilai uang yang diterima dari penjualan yang merupakan perkalian antara jumlah produksi dengan harga jual. Rata-rata jumlah penerimaan petani pada usahatani tanaman jernang di Desa Lamban Sigatal Kecamatan Pauh dapat dilihat pada Tabel 6 sebagai berikut:

Tabel 6. Rata-Rata Penerimaan Usahatani Jernang Di Desa Lamban Sigatal Kecamatan Pauh Sarolangun Tahun 2021

\begin{tabular}{|c|c|c|}
\hline No & Keterangan & Jumlah Rata-Rata \\
\hline 1 & Produksi (Kg/Ha/Periode) & 1.080 \\
\hline 2 & $\operatorname{Harga}(\mathrm{Rp} / \mathrm{Kg})$ & 80.000 \\
\hline 3 & Penerimaan ( $\mathrm{Rp} / \mathrm{Ha} /$ Periode $)$ & 86.400 .000 \\
\hline
\end{tabular}

Sumber : Data Primer yang diolah 2021

Berdasarkan hasil penelitian di lapangan diperoleh hasil rata-rata produksi tanaman jernang yaitu $1.080 \mathrm{Kg}$ dengan rata-rata harga tanaman jernang yaitu Rp. $80.000 / \mathrm{Kg}$. Berdasarkan jumlah hasil produksi per periode dan harga jual per satuan Kg produksi didapatkan hasil rata-rata penerimaan usahatani jernang per periode panen adalah sebesar 86.400.000. Besar kecilnya penerimaan petani di lokasi penelitian tergantung dengan banyaknya buah yang dihasilkan serta harga jual yang berlaku pada saat penjualan.

\section{E. Pendapatan Usahatani Jernang}

Pendapatan usahatani adalah selisih antara total penerimaan dan total biaya produksi usahatani jernang di Desa Lamban Sigatal Kecamatan Pauh selama proses produksi dapat dilihat pada Tabel 7 sebagai berikut:

Tabel 7. Rata-Rata Pendapatan Usahatani Jernang Di Desa Lamban Sigatal Kecamatan Pauh Sarolangun Tahun 2021

\begin{tabular}{ccc}
\hline No & Keterangan & Jumlah (Rp/Periode) \\
\hline 1 & Penerimaan & 86.400 .000 \\
2 & Biaya & 10.597 .544 \\
3 & Pendapatan & 75.802 .456 \\
\hline
\end{tabular}

Sumber : Data Primer yang diolah 2021

Berdasarkan Tabel 7 dapat diketahui bahwa rata-rata pendapatan petani jernang di Desa Lamban Sigatal Kecamatan pauh adalah Rp. 75.802.456/Periode. Dari data tersebut terlihat bahwa total penerimaan lebih besar dari total biaya yang dikeluarkan, hal ini berarti penerimaan petani bisa menutupi semua biaya yang dikeluarkan dalam proses produksi usahatani jernang di daerah penelitian. Hasil rata-rata pendapatan petani bisa untuk membantu memenuhi kebutuhan hidup dan menunjang keuangan rumah tangga petani.

Dengan rata-rata satu periode panen sama dengan 3 bulan sekali maka pendapatan tersebut berarti dalam 3 bulan sebesar Rp. 75.802.456 atau setara dengan Rp. 25.267 .485 per bulan. Angka ini lebih rendah dari estimasi yang dinyatakan oleh (Arifin, 2008) bahwa keuntungan yang diperoleh dari 1 Ha Jernang per tahun adalah $35-38$ Juta Rupiah. Dengan demikian penghasilan petani dapat dikatakan tinggi, meskipun mereka harus terus melakukan perawatan tanaman jernang dan menunggu pemanenan dalam jangka waktu yang lama.

\section{F. Efisiensi Teknis usahatani jernang}

Model yang digunakan dalam mengestimasi fungsi efisiensi teknis usaha tani jernang di desa Lamban Sigatal adalah model Stochastic Production Frontier. Pendekatan Stochastic Frontier menggunakan metode penduga 
Siti Abir Wulandari dan Jonathan Tio Pande Simbolon. Pendapatan dan Efisiensi Teknis Usaha Tani Jernang (Daemonorops Draco) di Desa Lamban Sigatal Kecamatan Pauh Kabupaten Sarolangun Provinsi Jambi

berupa Maximum Likelihood Estimated (MLE). Metode MLE digunakan untuk menganalisis faktor-faktor yang mempengaruhi produksi dan tingkat efisiensi teknis usahatani jernang di Desa Lamban Sigatal

Variabel independent yang diduga berpengaruh terhadap produksi jernang sebanyak 4 variabel, yaitu luas lahan (S1), bibit (S2), pupuk (S3), dan obat-obatan (S4).

\section{Pendugaan Fungsi Produksi Stokastik}

Pendugaan parameter fungsi produksi Cobb-Douglas dengan metode OLS menunjukkan kinerja rata-rata (best fit) dari proses produksi petani pada tingkat teknologi yang ada. Hasil estimasi model fungsi produksi CobbDouglas dengan metode OLS dapat dilihat pada Tabel 8.

Tabel 8. Hasil estimasi fungsi produksi stokastik dengan metode OLS

\begin{tabular}{lccc}
\hline \multicolumn{1}{c}{ Variabel } & Dugaan Koefisien & t-rasio & t-tabel \\
\hline Intersep $(\mathrm{So})$ & $-0.84030473 \mathrm{E}+00$ & $0.21664666 \mathrm{E}-05$ & 1.812 \\
Luas lahan $\left(\mathrm{S}_{1}\right)$ & $-0.12197297 \mathrm{E}+00$ & $-0.17234941 \mathrm{E}-05$ & 1.812 \\
Bibit $\left(\mathrm{S}_{2}\right)$ & $0.11274090 \mathrm{E}+01$ & $0.15930421 \mathrm{E}-04$ & 1.812 \\
Pupuk $\left(\mathrm{S}_{3}\right)$ & $0.34703407 \mathrm{E}-05$ & $0.46766106 \mathrm{E}-05$ & $1.812^{*}$ \\
Obat-obatan $\left(\mathrm{S}_{4}\right)$ & $0.66346502 \mathrm{E}-07$ & $0.40237242 \mathrm{E}-06$ & $1.812^{*}$ \\
\hline
\end{tabular}

Sigma-squared $0.77952981 \mathrm{E}-02$

$\log$ likelihood OLS $\quad 0.18163670 \mathrm{E}+02$

Keterangan:

*) Signifikan pada $\alpha=5 \%$.

Berdasarkan Tabel 8, dapat dilihat nilai sigma-squared sebesar 7,79 menunjukkan varians error term (ui) indeks efisiensi teknis menuju satu. Hanya dua variabel yang signifikan yaitu pupuk $\left(\mathrm{S}_{3}\right)$ dan obat-obatan $\left(\mathrm{S}_{4}\right)$, sedangkan variabel lainnya tidak signifikan mempengaruhi produksi jernang. Pendugaan fungsi produksi stokastik (stochastic frontier production) menunjukkan tidak begitu baik jika menggunakan metode OLS (Ordinary Least Squares). Selanjutnya, pendugaan fungsi produksi stokastik (stochastic frontier production) menggunakan metode MLE (Maximum Likelihood Estimation) lebih sesuai dengan beberapa uji statistik yang mendukung pada tingkat teknologi produksi jernang yang diterapkan petani. Pendugaan model fungsi produksi stochastic frontier production dengan menggunakan metode MLE disajikan dalam Tabel 9.

Menurut (Coelli \& Prasada Rao, 2005) untuk menduga model yang baik, digunakan indikator berupa signifikansi variabel terhadap produksi minimal satu. Nilai sigma-squared $\left(\sigma^{2}\right)$ harus mendekati nol dan nilai gamma (y) mendekati angka satu. Kemudian LR test > LR tabel dan nilai log-likelihood MLE harus lebih besar dari loglikelihood OLS. Sehingga model dapat dikatakan baik dan dapat digunakan untuk pendugaan efisiensi teknis.

Pada Tabel 9 dapat dilihat nilai log-likelihood MLE $(0,462)$ lebih besar dari nilai log-likelihood OLS $(0,181)$, berarti bahwa fungsi produksi dengan metode MLE ini baik dan dapat digunakan. Nilai sigma-squared $\left(\sigma^{2}\right)$ sebesar 0,758 menunjukkan error term (ui) efisiensi terdistribusi normal karena relative besar menuju satu. Nilai gamma (y) sebesar 0,9999 mengindikasikan bahwa 99,99 persen dari error term yang terdapat dalam fungsi produksi disebabkan oleh inefisiensi teknis, sisanya sebesar 0,01 persen disebabkan oleh variabel kesalahan acak seperti cuaca, hama, dan sebagainya. Oleh karena itu, keberadaan inefisiensi teknis dapat ditunjukkan dalam model fungsi produksi stochastic frontier. LR test > LR tabel, maka terima H0. Artinya, setiap variabel yang digunakan dalam proses produksi memiliki pengaruh terhadap tingkat efisiensi teknis petani. Model yang terbentuk dapat dilihat pada persamaan dibawah ini:

Tabel 9. Hasil pendugaan model fungsi produksi dengan metode MLE

\begin{tabular}{lccc}
\hline \multicolumn{1}{c}{ Variabel } & Dugaan Koefisien & t-rasio & t-tabel \\
\hline Intersep $(\mathrm{So})$ & $0.90224289 \mathrm{E}+00$ & $0.92298755 \mathrm{E}+00$ & 1.812 \\
Luas lahan $\left(\mathrm{S}_{1}\right)$ & $-0.77456082 \mathrm{E}-01$ & $-0.28535645 \mathrm{E}+00$ & $1.812^{*}$ \\
Bibit $\left(\mathrm{S}_{2}\right)$ & $0.10225798 \mathrm{E}+01$ & $0.18316865 \mathrm{E}+01$ & 1.812 \\
Pupuk $\left(\mathrm{S}_{3}\right)$ & $0.11709780 \mathrm{E}+00$ & $0.18310938 \mathrm{E}+00$ & $1.812^{*}$ \\
Obat-obatan $\left(\mathrm{S}_{4}\right)$ & $-0.71024473 \mathrm{E}-02$ & $-0.67415019 \mathrm{E}-01$ & $1.812^{*}$ \\
\hline Sigma-squared $\left(\sigma^{2}\right)$ & 0,758 & & \\
Gamma $(\gamma)$ & 0,999 & & \\
LR test of the one-sided error & 0,462 & & \\
Log-likelihood $M L E$ & 0,562 & & \\
\hline
\end{tabular}

Keterangan: *) Signifikan pada $\alpha=5 \%$. 


\section{Interpretasi parameter dugaan fungsi produksi stokastik}

Berdasarkan hasil perhitunggan fungsi produksi stochastic frontier dengan metode MLE, didapatkan hasil bahwa faktor bibit, dan pupuk berkorelasi positif dan berpengaruh nyata terhadap efisiensi usahatani jernang. Berikut intepretasi dari model fungsi produksi stochastic frontier yang terbentuk:

Penggunaan luas lahan garapan pada usahatani jernang di Desa Lamban Sigatal bernilai negatif dan berpengaruh nyata terhadap produksi jernang pada $\alpha=5 \%$ dengan nilai elastisitas negatif. Hal ini mengindikasikan bahwa terdapat beberapa hal yang tidak efektif dalam produksi jernang atau mesih terdapat beberapa Teknik penanaman jernang yang belum diketahui oleh petani karena tanamna jernang termasuk kategoritanamn yang baru dibudidayakan oleh petani sehingga belum banyak hasil penelitian yang bisa diinformasikan kepada petani.

Faktor bibit pada usahatani jernang di Desa Lamban Sigatal bernilai positif dan tidak berpengaruh nyata terhadap produksi jernang pada $\alpha=5 \%$. Hal ini mengindikasikan bahwa terdapat beberapa hal yang belum efektif dalam penggunaan bibit. Karena bibit yang ditanam petani diperoleh dengan cara membeli ditoko pertanian dan tanaman jernang membutuhkan perawatan intensif sehingga peningkatan perawatan tanaman diharapkan mampu maningkatkan produksi. Faktor produksi pupuk memiliki nilai positif dan berpengaruh nyata terhadap produksi usahatani jernang pada taraf $\alpha=5 \%$ dengan nilai elastisitas positif. Jumlah pupuk pada usahatani jernang masih bisa ditingkatkan agar dapat meningkatkan produksi. Begitupun dengan kombinasi penggunaan pupuk kandang, urea dan NPK sehingga mampu meningkatkan produksi. belum berimbangnya unsur hara yang diperlukan tanaman jernang terutama unsur Pospor dan Kalium pada masa generatif kemungkinan menyebabkan terjadi pengaruh sebaliknya terhadap produksi jernang.

Faktor obat-obatan pada usahatani jernang di Desa Lamban Sigatal bernilai negatif dan berpengaruh nyata terhadap produksi jernang pada $\alpha=5 \%$ dengan nilai elastisitas negatif. Penggunaan obat-obatan yang tepat dan dan sesuai dosis akan mampu menjaga tanaman jernang dari serangan hama yang diharapkan mampu maningkatkan produksi. Karena selama ini dosis yang digunakan petani tidak berdasarkan dosis yang dianjurkan sehingga kelebihan penggunaan akan merusak tanaman.

\section{Sebaran Efisiensi Teknis Usahatani jernang}

Pencapaian efisiensi teknis dianalisis dengan menggunakan fungsi produksi stochastic frontier. Rata-rata efisiensi teknis yang dicapai petani jernang di desa Lamban Sigatal adalah sebesar 98\%. Apabila dilihat dari sebarannya, efisiensi teknis yang dicapai oleh petani responden ada pada kisaran 97,7 \% sampai 99,8\% Tingkat efisiensi teknis petani dikatakan cukup efisien bila nilainya lebih besar dari 0,7. Mayoritas petani memiliki efisiensi teknis diatas 0,7. Dapat disimpulkan bahwa sebagian besar petani jernang sudah efisien, karena tingkat efisiensi teknis dinilai sudah tinggi menunjukkan petani sudah menerapkan sistem usaha tani jernang dengan baik. Menurut (Varina et al., 2020) peningkatan ketrampilan teknis dan kapabilitas manajerial pekebun dan penggunaan teknologi baru yang lebih maju tetap harus difocuskan sebagai kebijakan peningkatan produksi.

\section{KESIMPULAN}

Berdasarkan hasil penelitian dan pembahasan maka dapat disimpulkan yaitu sebagai berikut:

1. Jarak tanam tanaman jernang $8 \times 4 \mathrm{~m}$ dengan menggunakan pupuk organik dan anorganik. Pupuk diberikan dengan beberapa tahapan, pertama diberikan sebelum atau bersamaan dengan waktu penanaman, pupuk dimasukkan ke dalam lubang tanam dengan dosis $2 \mathrm{~kg}$ per lubang tanam atau NPK 100 gr per lubang tanam. Selanjutnya pupuk lanjutan dimulai setelah tanaman berumur 6 bulan. NPK dengan dosis antara 50-100 gram per tanaman yang dilakukan setiap 6 bulan. Pemupukan pupuk kompos atau pupuk kandang juga dilakukan dengan cara diletakkan disekitar tanaman. Pemanenan buah rata-rata dilakukan 3 bulan sekali untuk mendapatkan hasil yang optimal dan rata-rata hasil produksi jernang adalah $1.080 \mathrm{Kg} /$ Periode. Pemasaran dilakukan secara tidak langsung dengan mengantarkan hasil jernang ke lokasi pembeli.

2. Rata-rata total biaya adalah sebesar Rp. 10.597.544 /Periode terdiri dari biaya tetap sebesar Rp. 70.550/Periode Panen dan biaya tidak tetap sebesar Rp. 10.526.993//Periode Panen. Rata-rata penerimaan yang diperoleh petani sebesar Rp. 86.400.000 /Periode Panen.

3. Pendapatan petani jernang di Desa Lamban Sigatal Kecamatan Pauh sebesar Rp. 75.802.456/Periode Panen. Dengan rata-rata satu periode panen sama dengan 3 bulan sekali maka pendapatan tersebut berarti dalam 3 bulan sebesar Rp. 75.802 .456 atau setara dengan Rp. 25.267 .485 per bulan.

4. Rata-rata efisiensi teknis yang dicapai petani jernang di desa Lamban Sigatal adalah sebesar 98\%. Apabila dilihat dari sebarannya, efisiensi teknis yang dicapai oleh petani responden ada pada kisaran 97,7 \% sampai 99,8\%. Petani jernang sudah efisien, karena tingkat efisiensi teknis dinilai sudah tinggi menunjukkan petani sudah menerapkan sistem usaha tani jernang dengan baik 
Siti Abir Wulandari dan Jonathan Tio Pande Simbolon. Pendapatan dan Efisiensi Teknis Usaha Tani Jernang (Daemonorops Draco) di Desa Lamban Sigatal Kecamatan Pauh Kabupaten Sarolangun Provinsi Jambi

DAFTAR PUSTAKA

Aigner, D., Lovell, C. A. K., \& Schmidt, P. (1977). Formulation and estimation of stochastic frontier production function models. Journal of Econometrics, 6(1), 21-37. https://doi.org/10.1016/0304-4076(77)90052-5

Arifin, W. (2008). Jernang: Tanaman Konservasi bernilai Ekonomis Tinggi. https://weinarifin.wordpress.com/2008/12/15/jernang-tanaman-konservasi-bernilai-ekonomis-tinggi-melihatbudidaya-rotan-jernang-di-propinsi-jambi/

Coelli, T. J., \& Prasada Rao, D. S. (2005). Total factor productivity growth in agriculture: a Malmquist index analysis of 93 countries, 1980-2000.

Debertin, D. (2013). A Brief Introduction to the History of Computing in Agricultural Economics. In Staff Papers. https://doi.org/10.22004/ag.econ.158674

Sahwalita. (2014). Budidaya Rotan Jernang. In Balai Penelitian Kehutanan Palembang (pp. 9-14).

Sarikun, S., M, I. A., \& Hardiansyah, G. (2019). Pemanfaatan Jenis Rotan Oleh Masyarakat Dusun Mungguk Meranang Kecamatan Sungai Laur Kabupaten Ketepang. Jurnal Hutan Lestari, 7(4). https://doi.org/10.26418/jhl.v7i4.37863

Satrio, \& Aji, B. (2016). Analisis Pengaruh Jumlah Penduduk Usia Produktif, Jumlah Lulusan SMA Dan Investasi Terhadap Pengangguran Terdidik Di Provinsi Jawa Tengah Tahun 1985-2014.

Statistik, B. P. (2018). Statistik Kelapa Sawit Indonesia 2018. In Badan Pusat Statistik.

Suratiyah, K. (2015). Ilmu Usahatani. In Jakarta.

Varina, F., Hartoyo, S., Kusnadi, N., \& Rifin, A. (2020). Efficiency Of Oil Palm Smallholders In Indonesia: A MetaFrontier Approach. Jurnal Manajemen \& Agribisnis. https://jurnal.ipb.ac.id/index.php/jmagr/article/view/34144/20984

Waluyo, T. K. (2017). Teknik Ekstraksi Tradisional Dan Analisis Sifat-Sifat Jernang Asal Jambi. Jurnal Penelitian Hasil Hutan, 26(1), 30-40. https://doi.org/10.20886/JPHH.2008.26.1.30-40

Wicaksono, B., \& Adhi, A. K. (2014). Analisis Tataniaga Buah Jernang Rotan (Studi Kasus: Hutan Desa Lamban Sigatal, Kecamatan Pauh, Kabupaten Sorolangun, Provinsi Jambi) [Institut Pertanian Bogor]. http://repository.ipb.ac.id/handle/123456789/73186 